\title{
A Cross-sectional Study on Zoonotic and Reverse Zoonotic Transmission of Tuberculosis in Central Ethiopia
}

\author{
Tefera Woldemariam \\ Hawassa University \\ Gezahegne Mamo \\ Addis Ababa University, College of Veterinary Medicine and Agriculture \\ Aboma Zewude \\ Ethiopian Public Health Institute \\ Mahlet Chanyalew \\ Addis Ababa University \\ Temesgen Mohammed \\ Addis Ababa University \\ Gobena Ameni ( $\sim$ gobena.ameni@aau.edu.et) \\ Addis Ababa University https://orcid.org/0000-0003-3987-0671
}

\section{Research article}

Keywords: Ethiopia, Tuberculosis, Reverse Zoonosis, Zoonosis

Posted Date: June 1st, 2020

DOI: https://doi.org/10.21203/rs.3.rs-26154/v1

License: (c) (i) This work is licensed under a Creative Commons Attribution 4.0 International License. Read Full License 


\section{Abstract}

Background: The zoonotic transmission of tuberculosis (TB) from cattle to humans has long been recognized while its reverse zoonotic transmission from humans to animals has recently been reported. The socioeconomic situations of the rural communities of Ethiopia are conducive for the zoonotic and reverse zoonotic transmission of TB between cattle and human. The objective of this study was to investigate the zoonotic and reverse zoonotic transmission TB between humans and cattle central Ethiopia.

Methods: To achieve this objective a cross-sectional study was conducted on 1896 cattle slaughtered in two abattoirs and 392 TB suspicious human subjects visiting health institutions for treatment. Post mortem examination, mycobacteriological culture, and spoligotyping were used for the study. In addition, the Spoligotype International Types and VNTR (variable number of DNA tandem repeats) International Types (SITVIT2) database and the online "Run TB-Lineage" were used to identify SIT and lineages of the human and cattle isolates.

Results: Gross TB lesion was detected in 4.2\% (80/1896) the slaughtered cattle and predominantly (52.5\%) found in the thoracic cavity. But culture positivity was only $26.3 \%(21 / 80)$ in suspicious lesions. Of the 21 cattle isolates, $12(57.2 \%)$ were $M$. bovis while the remaining nine (42.8\%) were M. tuberculosis. SIT50, SIT118 and SIT1318 were isolated from both humans and cattle. Similar to the low culture yield in cattle tissues, only 22\% (86/392) the sputa from TB suspicious humans were culture positive. These 86 human isolates were classified into 81 M. tuberculosis, three M. africanum and two M. bovis by spoligotyping. The two human M. bovis isolates had the pattern of SB1443, which was not isolated from cattle in this study.

Conclusion: The zoonotic and reverse zoonotic transmissions of TB were confirmed in Ethiopia by the isolation of two $M$. bovis from human and isolation of nine M. tuberculosis from cattle, which suggested higher role of M. tuberculosis in cattle compared to the role of $M$. bovis in humans.

\section{Background}

Bovine tuberculosis (bTB) is a chronic disease animals characterized by progressive development granulomatous lesions or tubercles in the lymph nodes, lung tissue and or other organs. BTB is caused by members of the Mycobacterium tuberculosis ( $M$. tuberculosis) complex primarily by $M$. bovis, and to a lesser extent $M$. tuberculosis. The disease causes significant economic losses to the Agriculture Sector and public health problem in causing zoonotic TB in humans. According to the World Organization for Animal Health, 82 (44\%) of the 188 countries and territories reported the presence of bTB during January 2017 and June 2018 [1]. Thus, the disease is found throughout the world although most of the developed countries have reduced or eliminated it from their cattle populations except in limited areas where wild animals are interfering with their control programs being reservoirs of the infection. On the other hand, the disease is prevalent in many African countries and in parts of Asian countries [1-4]. The widespread of bTB in animal populations in developing countries is due to the lack of or inadequate control measures for the socioeconomic problems associated with the presently available test and slaughter control measure [4].

The direct correlation between $M$. bovis infection in cattle and zoonotic TB in the human population has been well documented in industrialized countries [4]. Zoonotic TB is caused by $M$. bovis and transmitted from animals to humans through consumption of foods infected animals and through inhalation of cough droplets from infected animals during close physical contact with them. Zoonotic TB is also an occupational hazard for farmers, abattoir workers, butchers and veterinary professionals.

Epidemiological studies of TB in cattle and in humans in Zambia [5] and in Ethiopia [6] indicated associations between tuberculin-positive cattle and human TB. In Zambia, it was observed that households that reported a TB case within the last one year were seven times more likely to own herds containing tuberculin-positive cattle. Similarly, tuberculin positivity was three-fold higher in cattle owned by farmers with active TB than in those owned by farmers who did not have active TB in Ethiopia. These observations could suggest the transmission of mycobacteria between humans and cattle, which could be the transmission of $M$. bovis from cattle to humans or the transmission of $M$. tuberculosis from humans to cattle. A few studies in Ethiopia reported the isolation of $M$. bovis from sputum and fine needle aspirate of human TB cases [7-8]. According the literature review reported earlier [9], in countries where bTB is still common and pasteurization of milk is not practiced, an estimated 10-15\% of human TB 
is caused by $M$. bovis and the infections of $M$. bovis is thought to occur through drinking raw milk [10] and through inhalation in rural areas in people who live in close contact with cattle [11].

The few studies conducted in Ethiopia are limited in their geographic coverage and representations. Geographic regions such the East Shewa Zone of the central Ethiopia where dairy cattle and beef farming are widely practiced have not been considered. East Shewa Zone of central Ethiopia is prone to risk of transmission of mycobacteria between cattle and humans. There are many butchers in the area and cattle from the beef farms and nearby rural areas are slaughtered by butchers for selling raw meat and the area is known by the business of raw meat. In addition to beef cattle, dairy cows are kept by the farmers living in the towns and in the rural districts surrounding the towns. A significant percentage of raw milk are supplied to the consumers in living in the area. These common customs of raw milk and raw meat consumptions could facilitate the transmission of M. bovis from cattle to humans. On the other hand, Ethiopia stands $7^{\text {th }}$ in the 20 human TB burden countries with the incidence rate of 165 individuals per 100,000 population [12]. East Shewa Zone is one of the densely populated areas of Ethiopia with high rate of human mobility since the main road to the Port of Djibouti passes through the Zone. Therefore, there are conducive environment for the transmission of human TB, and there could be high chance of transmission of $M$. tuberculosis from humans to cattle because of the close physical contact between humans and their cattle. It is paramount important to investigate if there is transmission TB between cattle and humans since there are conducive epidemiological situations. The present study was conducted to investigate the zoonotic and reverse zoonotic transmission TB between humans and cattle East Shewa, central Ethiopia.

\section{Results}

\section{Prevalence of BTB in feedlots and dairy farms East Shewa}

The average lesion prevalence was 4.2\% (80/1896) in the two abattoirs. Lesion prevalence was 7.6\% (48/630) in cattle slaughtered at Bishoftu abattoir while it was 2.5\% (32/1266) in Adama abattoir (Table 1). However, only $26.3 \%$ of the 80 suspicious lesions were turned to be culture positive. The e distribution and frequency of lesions in different tissues of cattle was presented in Table 2. The highest proportion (52.5\%) of the lesion was recorded in the lungs and thoracic lymph nodes followed by the lymph nodes of the head and neck.

\section{Sputum culture positivity and demographic characteristics of the study subjects}

Table 3 shows selected demographic characteristics of the human TB suspicious cases, who were used a sources sputum at the two towns. Sputum culture positivity was only $21.9 \%$ (86/392). Fifty culture positive samples were from the samples collected from Adama while 36 were from Bishoftu. Culture positivity was 18.2\% (50/274) in samples collected from Adama Town while it was $30.5 \%(36 / 118)$ in samples collected from Bishoftu Town.

\section{Molecular identification of species and strains of mycobacteria}

\section{Animal isolates}

Of the 21 isolates, $12(57.2 \%)$ isolates were confirmed to be $M$. bovis while the remaining nine (42.8\%) were M. tuberculosis. The $12 \mathrm{M}$. bovis isolates were grouped into nine spoligotype patterns; three of which were clustered each consisting two isolates while the remaining six were singleton each consisting of one isolate (Table 4). Two of the nine $M$. bovis spoligotype patterns were shared types (SB1265 and SB1176) while the remaining seven types were orphans. Cattle isolates of M. tuberculosis were grouped into nine spoligotype patterns in which case one isolate constituted one spoligotype pattern. Four of the nine spoligotype patterns (SIT50, SIT117, SIT118 and SIT1318) were shared types while the remaining five were orphans (Table 4). Almost all (eight) of the nine spoligotypes of cattle isolates of $M$. tuberculosis were members of the Euro-American Lineage while the remaining one was a member of Indio-Oceanic Lineage.

\section{Human isolates}


A total of 86 human isolates were identified that were classified into $81 M$. tuberculosis, three M. africanum and two M. bovis (Table 5). The two isolates of $M$. bovis had SB1443 pattern, that has already been registered in $M$. bovis database. The spoligotype pattern of the human $M$. bovis isolates did not match with any of the patterns of the cattle M. bovis isolates. As indicated in Table 5,75\% (61/81) of the $M$. tuberculosis isolates were grouped under the shared spoligotypes while the remaining $25 \%$ (20/81) were grouped under orphan spoligotypes. The dominantly identified spoligotypes were SIT149, SIT53 and SIT118 each consisting of 18, 11 and six isolates, respectively. SIT50, SIT118 and SIT1318 which were isolated from cattle were also isolated from humans. Totally, the $81 \mathrm{M}$. tuberculosis isolates were grouped into 32 different spoligotype patterns and the majority (84.4\%) these patterns were members of the Euro-American Lineage followed by the East African-Indian Lineage (12.5\%) and Indio-oceanic Lineage (3.1\%).

The average lesion prevalence was $4.2 \%(80 / 1896)$ in the two abattoirs. Lesion prevalence was $7.6 \%(48 / 630)$ in cattle slaughtered at Bishoftu abattoir while it was 2.5\% (32/1266) in Adama abattoir (Table 1). However, only $26.3 \%$ of the 80 suspicious lesions were turned to be culture positive. The e distribution and frequency of lesions in different tissues of cattle was presented in Table 2. The highest proportion (52.5\%) of the lesion was recorded in the lungs and thoracic lymph nodes followed by the lymph nodes of the head and neck.

\section{Prevalence of BTB in feedlots and dairy farms East Shewa}

The average lesion prevalence was $4.2 \%(80 / 1896)$ in the two abattoirs. Lesion prevalence was $7.6 \%(48 / 630)$ in cattle slaughtered at Bishoftu abattoir while it was 2.5\% (32/1266) in Adama abattoir (Table 1). However, only $26.3 \%$ of the 80 suspicious lesions were turned to be culture positive. The e distribution and frequency of lesions in different tissues of cattle was presented in Table 2. The highest proportion (52.5\%) of the lesion was recorded in the lungs and thoracic lymph nodes followed by the lymph nodes of the head and neck.

\section{Sputum culture positivity and demographic characteristics of the study subjects}

Table 3 shows selected demographic characteristics of the human TB suspicious cases, who were used a sources sputum at the two towns. Sputum culture positivity was only $21.9 \%$ (86/392). Fifty culture positive samples were from the samples collected from Adama while 36 were from Bishoftu. Culture positivity was $18.2 \%$ (50/274) in samples collected from Adama Town while it was $30.5 \%$ (36/118) in samples collected from Bishoftu Town.

\section{Molecular identification of species and strains of mycobacteria}

\section{Animal isolates}

Of the 21 isolates, $12(57.2 \%)$ isolates were confirmed to be M. bovis while the remaining nine (42.8\%) were M. tuberculosis. The $12 \mathrm{M}$. bovis isolates were grouped into nine spoligotype patterns; three of which were clustered each consisting two isolates while the remaining six were singleton each consisting of one isolate (Table 4). Two of the nine $M$. bovis spoligotype patterns were shared types (SB1265 and SB1176) while the remaining seven types were orphans. Cattle isolates of M. tuberculosis were grouped into nine spoligotype patterns in which case one isolate constituted one spoligotype pattern. Four of the nine spoligotype patterns (SIT50, SIT117, SIT118 and SIT1318) were shared types while the remaining five were orphans (Table 4). Almost all (eight) of the nine spoligotypes of cattle isolates of $M$. tuberculosis were members of the Euro-American Lineage while the remaining one was a member of Indio-Oceanic Lineage.

\section{Human isolates}

A total of 86 human isolates were identified that were classified into 81 M. tuberculosis, three M. africanum and two M. bovis (Table 5). The two isolates of $M$. bovis had SB1443 pattern, that has already been registered in M. bovis database. The spoligotype pattern of the human $M$. bovis isolates did not match with any of the patterns of the cattle M. bovis isolates. As indicated in Table 5, 75\% (61/81) of the $M$. tuberculosis isolates were grouped under the shared spoligotypes while the remaining $25 \%$ (20/81) were grouped under orphan spoligotypes. The dominantly identified spoligotypes were SIT149, SIT53 and SIT118 each consisting of 18, 11 and six isolates, respectively. SIT50, SIT118 and SIT1318 which were isolated from cattle were also 
isolated from humans. Totally, the $81 \mathrm{M}$. tuberculosis isolates were grouped into 32 different spoligotype patterns and the majority (84.4\%) these patterns were members of the Euro-American Lineage followed by the East African-Indian Lineage (12.5\%) and Indio-oceanic Lineage (3.1\%).

Table 3 shows selected demographic characteristics of the human TB suspicious cases, who were used a sources sputum at the two towns. Sputum culture positivity was only $21.9 \%$ (86/392). Fifty culture positive samples were from the samples collected from Adama while 36 were from Bishoftu. Culture positivity was $18.2 \%$ (50/274) in samples collected from Adama Town while it was $30.5 \%$ (36/118) in samples collected from Bishoftu Town.

\section{Molecular identification of species and strains of mycobacteria}

\section{Animal isolates}

Of the 21 isolates, $12(57.2 \%)$ isolates were confirmed to be $M$. bovis while the remaining nine (42.8\%) were M. tuberculosis. The $12 \mathrm{M}$. bovis isolates were grouped into nine spoligotype patterns; three of which were clustered each consisting two isolates while the remaining six were singleton each consisting of one isolate (Table 4). Two of the nine $M$. bovis spoligotype patterns were shared types (SB1265 and SB1176) while the remaining seven types were orphans. Cattle isolates of M. tuberculosis were grouped into nine spoligotype patterns in which case one isolate constituted one spoligotype pattern. Four of the nine spoligotype patterns (SIT50, SIT117, SIT118 and SIT1318) were shared types while the remaining five were orphans (Table 4). Almost all (eight) of the nine spoligotypes of cattle isolates of $M$. tuberculosis were members of the Euro-American Lineage while the remaining one was a member of Indio-Oceanic Lineage.

\section{Human isolates}

A total of 86 human isolates were identified that were classified into 81 M. tuberculosis, three M. africanum and two M. bovis (Table 5). The two isolates of $M$. bovis had SB1443 pattern, that has already been registered in $M$. bovis database. The spoligotype pattern of the human $M$. bovis isolates did not match with any of the patterns of the cattle M. bovis isolates. As indicated in Table 5, 75\% (61/81) of the $M$. tuberculosis isolates were grouped under the shared spoligotypes while the remaining $25 \%(20 / 81)$ were grouped under orphan spoligotypes. The dominantly identified spoligotypes were SIT149, SIT53 and SIT118 each consisting of 18,11 and six isolates, respectively. SIT50, SIT118 and SIT1318 which were isolated from cattle were also isolated from humans. Totally, the $81 \mathrm{M}$. tuberculosis isolates were grouped into 32 different spoligotype patterns and the majority (84.4\%) these patterns were members of the Euro-American Lineage followed by the East African-Indian Lineage (12.5\%) and Indio-oceanic Lineage (3.1\%).

\section{Discussion}

In the present study, zoonotic transmission of $M$. bovis from cattle to humans and the reverse zoonotic transmission of $M$. tuberculosis from humans to cattle were investigated on 1896 cattle and 392 TB suspicious humans using mycobacterial culture and spoligotyping. TB suspicious lesions were sampled from cattle while sputum samples were the isolation mycobacteria and their identification using spoligotyping.

The result of the study indicated that the prevalence bTB was low in cattle slaughtered on the basis of lesion. This observation was similar with the observations made by other studies in different abattoirs in the country prior to the present study [21-23]. This observation can be related to the fact that almost all (about 98\%) the cattle that are slaughtered in the country are indigenous zebu breed which are relatively resistant to bTB [17,24-26]. Moreover, the majority of the zebu cattle that are slaughtered in Ethiopia are raised by the traditional farmers who raise their cattle under extensive cattle farming which does not favor the transmission of bTB [17]. Furthermore, the percentage of isolation of $M$. tuberculosis complex from lesions was low in this study similar to the results of other studies conducted earlier $[18,21,27]$. Such low percentage of isolation of M. tuberculosis complex in zebu cattle in Ethiopia could be associated with different factors. One of the factors could be the containment the $M$. tuberculosis complex in the granulomas, which are usually calcified and could lead to the death of M. tuberculosis complex leading to the low yield of culturing of such lesions. As observed during the last two decades, most of the lesions detected in 
zebu cattle were localized to one anatomical site and calcified [17,25-26]. The other factor could be human errors that may be introduced during the transportation, storage and processing of the lesioned tissue for culturing.

The culture of positivity the sputum samples collected from TB suspicious human cases was also low. Similar to this observation, earlier study in Ethiopia reported low percentage of isolation of M. tuberculosis from the sputum of TB patients [28]. The same study indicated that $83.2 \%$ (247/297) pulmonary TB suspected patients had a negative smear results for acid fast bacilli. The chance of isolation of $M$. tuberculosis complex from smear negative TB cases low. Culture positivity of sputum is directly related to the availability of the bacilli in the sputum, which can also be affected on the nature of the granuloma. If the granuloma is dense and solid, the chance of excretion of the bacilli in the sputum is minimal, which in turn leads the low yield of sputum culture. In addition, if sputum proper is not collected, and if the sputum storage and processing for culture are not performed using the optimum procedures, the yield of sputum culture is low.

In the present study, M. bovis was isolated from human TB patients while on the other hand, $M$. tuberculosis was isolated from TB lesions of cattle. Thus, this study indicated that TB is a good example of zoonosis and reverse zoonosis. Similarly, earlier studies reported the isolation of M. bovis from human TB patients in Ethiopia although the percentage of isolation was low [2933]. Besides, $M$. tuberculosis was isolated from TB lesions of cattle in Ethiopia and in other countries [18,29,34-37]. Moreover, $M$. tuberculosis was also isolated from other species domestic animals and zoo animals [38-40]. Although such studies are in generally scarce in Africa, the isolation of M. tuberculosis was reported from animals in few African countries [41-42]. The possible sources of infection of animals with $M$. tuberculosis could be sputum, urine and feces of humans, which arise from active cases of human TB in the respiratory tract, urinary tract or gastrointestinal tract, respectively [43].

The present studies and earlier Ethiopian studies reported greater percentage of isolation of M. tuberculosis (reverse zoonosis) in cattle tissues as compared to the percentage of the isolation of $M$. bovis from humans. This observation could suggest that regarding $B$ transmission in Ethiopia reverse zoonosis is more important than zoonosis, which is directly influenced by the prevalence TB in the primary host. The prevalence of bTB in the indigenous cattle, which constitute about $98 \%$ of the Ethiopian cattle population is low, and subsequently, there is a low chance of transmission of bTB from cattle to humans. On the other hand, Ethiopia is one of the 10 countries of the world with high burden of human TB [12], which gives a high chance of transmission of $M$. tuberculosis from humans to cattle because of the sociocultural link of Ethiopian farmers with their cattle. But, contrary to the Ethiopian reports, studies from other African countries reported the isolation of higher percentage of $M$. bovis from humans as compared to the percentage of isolation of $M$. tuberculosis from animals [8, 44-46].

\section{Conclusion}

Zoonotic transmission TB was observed by the isolation of two M. bovis from human subjects while the reverse zoonotic transmission was confirmed by isolation of nine M. tuberculosis isolates from cattle tissues. This observation could suggest that the prevalence of $M$. tuberculosis infection in cattle is higher than the prevalence of M. bovis infection in humans.

\section{Methods}

\section{Study design}

This study was a cross-sectional study in which the zoonotic transmission of $M$. bovis from cattle to humans and the reverse zoonotic transmission of $M$. tuberculosis from humans to cattle were investigated in the East Shewa Zone of central Ethiopia.

\section{Study setting}

The field sample collection part of the study was conducted from August 2015 to August 2016 at Adama and Bishoftu towns East Shewa Zone of Oromia Regional State, central Ethiopia (Figure 1). Bishoftu and Adama towns are located at $47 \mathrm{~km}$ and $95 \mathrm{~km}$ southeast of Addis Ababa, respectively. These two towns are known by beef production and selling of beef meat. Cattle from the beef farms and rural areas surrounding the two towns are slaughtered in the abattoirs located at these towns and raw meat consumption is very common in the area. In addition to beef cattle, dairy cows are kept by the farmers living in these towns 
and in the rural districts surrounding the two towns. Thus, a significant percentage of raw milk are supplied to the consumers in living in these towns and the surrounding districts. Unfortunately, as BTB is prevalent in dairy farms in the country and these dairy farms are not expected to be free from the disease.

\section{Sample size}

The determination was based on the availability of fund and logistics to support the research activities of the project. Since the main objective of this research was to evaluate the transmission of $M$. tuberculosis between cattle and humans, it was tried to collect the maximum number of samples by examining large number of cattle and also collecting large number sputum samples. No statistical calculation was used to estimate the sample size in both human and cattle studies. Thus, the available fund and logistics could cover the examination of 1,896 cattle at the two (1266 at Adama and 630 at Bishoftu) abattoirs. In addition, 392 (274 from Adama and 118 from Bishoftu) sputum samples were collected from the two towns.

\section{Participants of the study}

The study subjects were comprised of cattle slaughtered at these two abattoirs and human TB patients who visited the heath care centers at the two towns during the study period. Post mortem examination for BTB was conducted on cattle, which were originated from the beef farms in located either at the two towns or in the surrounding districts. Similarly, sputum samples of individuals who were living in these towns and or the surrounding districts plus who had connections with either dairy or beef cattle were used for bacteriological and molecular analysis.

\section{Variables}

The primary outcome was the isolation the same species of $M$. tuberculosis complex from both cattle and humans, which could suggest the transmission of TB between cattle and humans. Other secondary outcomes were percentage of cattle with TB lesion in their tissues and the percentage of suspicious TB lesion that were positive by culture and spoligotyping. With regard to the human study, the secondary outcome was the percentage of TB suspicious patients who were positive by culture and spoligotyping. The diagnostic criteria for cattle study were gross BTB lesion, and confirmation by culture and spoligotyping. While the diagnostic criteria for human study was clinical examination by the responsible health professionals in the health care centers, and then further confirmation of culturing of sputum and spoligotyping the isolates. The final confirmation of the transmission of $M$. tuberculosis complex species between cattle and humans was made by spoligotyping.

\section{Sample collection}

As the primary objective the study was to confirm the existence of the transmission of $M$. tuberculosis species between humans and animals, focus was made on the search of BTB lesions in tissues of cattle and then collection of suspicious lesions. Data on the body condition and origin of each study animal were collected. However, data on the age of the animal not collected. In addition, the tissues from which suspicious lesions detected were recorded. The BTB suspicious tissue samples were collected into universal bottles with normal saline and transported to the TB laboratory Aklilu Lemma Institute of Pathobiology of the Addis Ababa University in cold chain. In total, 1896 cattle were examined at the two abattoirs and 80 BTB suspicious lesions were collected for culturing. The number of the animal recruited was dependent on the availability of logistics and convenience of the slaughterhouses.

Sample collection in humans was conducted as part of the routine diagnostic procedures of TB and sputum samples submitted to the hospitals and health centers by 392 TB suspicious cases for diagnosis were shared. Thus, 274 sputum samples were collected from Adama Town while 118 sputum samples were collected from Bishoftu Town. The sputa samples were transported in in cold chain to the TB laboratory of the Aklilu Lemma Institute of Pathobiology of the Addis Ababa University for culturing.

\section{Post-mortem examination and tissue sampling}

Body condition scoring was made using the method developed earlier based on the different prominent anatomical structures such as the visibility of the ribs, the gluteal muscles, tuber coxae, the head of the tail, transverse processes and others [13-14] 
Postmortem examination was performed following the protocol set previously by another researcher [15]. Each of the seven lobes of the lungs were thoroughly inspected and palpated for any suspicious gross TB lesions. Similarly, mandibular, retropharyngeal, cranial and caudal mediastinal, left and right bronchial, hepatic, and mesenteric lymph nodes were sliced into $2 \mathrm{~mm}$ size sections and then inspected for the presence of visible lesions according to the protocol described earlier [16-17]. The tissues showing macroscopic lesions compatible with bTB were collected into universal bottle in $0.9 \%$ saline solution and then transported to the laboratory in cold chain. A total of 80 suspicious lesions were collected from the total 1896 cattle investigated, and processed for culturing as described below.

\section{Culturing of sputum and tissues samples}

Regular visits were made to the hospital and health centers in the study area for collection of sputum samples that were submitted to the routine diagnosis of TB. In total, 392 sputum samples were collected and transported to the TB laboratory in cold chain for culturing. The samples were stored at $-20^{\circ} \mathrm{C}$ freezer until being thawed and processed for culturing. Culturing of sputum samples was done on Lowenstein-Jensen $(\mathrm{LJ})$ media following the procedure used earlier [6]. Similarly, suspicious tissue samples were processed for culturing on LJ media following the procedure used by other researchers [1]. The colonies were harvested and re-suspended in sterile distilled water and heat-killed at $80^{\circ} \mathrm{C}$ for 50 minutes so that mycobacterial DNA is released and used for subsequent spoligotyping.

\section{Spoligotyping of mycobacterial isolates}

Spoligotyping was performed on 107 M. tuberculosis complex isolates at the Aklilu Lemma Institute of Pathobiology, Addis Ababa University, following the standard operating procedure that was used by Berg et al. [18] and primarily developed by Kamerbeek et al. [19]. The DNA released by heat-killing of the colonies was used as a template to amplify the direct repeat (DR) region of $M$. tuberculosis complex by polymerase chain reaction (PCR) using oligonucleotide primers derived from the DR sequence, RDa (5'GGTTTTGGGTTTGAACGAC3') and RDb (5'CCGAGAGGGGACG GAAAC3') primers [19]. The total volume of the reaction the PCR reaction mixture was $25 \mu \mathrm{l}$ and constituted of $12.5 \mu \mathrm{l}$ of HotStarTaq Master Mix (Qiagen; this solution provides a final concentration of $1.5 \mathrm{mM} \mathrm{MgCl} 2$ and $200 \mathrm{mM}$ of each deoxoribonucleotide triphosphate), $2 \mu \mathrm{l}$ of each primer ( $20 \mathrm{pmol}$ each), $5 \mu \mathrm{l}$ suspension of DNA template (approximately 10-50 ng), and $3.5 \mu$ l Qiagen water. The mixture was heated for 15 minutes at $96^{\circ} \mathrm{C}$ and then subjected to 30 cycles of 1 minute at $96^{\circ} \mathrm{C}, 1$ minute at $55^{\circ} \mathrm{C}$, and 30 seconds at $72^{\circ} \mathrm{C}$, and the final extension at $72^{\circ} \mathrm{C}$ for $10 \mathrm{~min}$. Immediately before running spoligotyping, the PCR product was denatured using thermocyler at $96^{\circ} \mathrm{C}$ for 10 minutes and then removed from the thermocycler and kept on ice so as to prevent renaturing of the PCR products. Thereafter, the denatured PCR product was loaded onto a membrane covalently bounded with a set of 43 oligonucleotides, each corresponding to one of the unique spacer DNA sequence within the DR locus of $M$. tuberculosis complex and then hybridized at $60^{\circ} \mathrm{C}$ for $1 \mathrm{~h}$. After hybridization, the membrane was washed twice for 10 minutes in $2 x$ SSPE (1x SSPE is $0.18 \mathrm{M} \mathrm{NaCl}, 10 \mathrm{mM}$ $\mathrm{NaH}_{2} \mathrm{PO}_{4}$, and $1 \mathrm{mM}$ EDTA [pH 7.7])-0.5\% sodium dodecyl sulfate at $60^{\circ} \mathrm{C}$ and then incubated in $1: 4000$ diluted streptavidinperoxidase (Boehringer) for $1 \mathrm{~h}$ at $42^{\circ} \mathrm{C}$. The membrane was washed twice for 10 minutes in $2 \times \mathrm{SSPE}-0.5 \%$ sodium dodecyl sulfate at $42^{\circ} \mathrm{C}$ and rinsed with $2 \times$ SSPE for 5 minutes at room temperature. Hybridizing DNA was detected by the enhanced chemiluminescence method (Amersham, Biosciences, Amersham, UK) and by exposure to X-ray film (Hyperfilm ECL, Amersham). A mixture of $10 \mathrm{ml}$ of ECL reagent 1 and $10 \mathrm{ml}$ of ECL reagent 2 was prepared, and then added onto the membrane, and the membrane was rinsed in the solution for $5 \mathrm{~min}$ at room temperature. Then, the membrane was attached onto a film in the dark room and placed in the cassette and incubated for 15 minutes a room temperature. Thereafter the film was removed and placed in a developer solution for 2 minutes. The film was removed from the developer and rinsed with tap water for 15 seconds and then placed in a fixer solution for 1 minute. Thereafter, the film was dried and used for interpretation of the result. The presence of the spacer was identified as a black square while absence of the spacer was identified as a white square on the film. Thereafter, the black squares were converted to 1 while the white squares were converted to 0 and then transferred to the spoligotype international types-VNTR international types (SITVIT) database for the identification of the spoligotype international types (SIT) and the lineages of the isolates.

\section{Data analysis}


Proportion was used to show the number of cattle with TB lesions. Tissue lesion and sputum culture positivity were presented using proportions. Comparisons of proportions was made by using chi-square $\left(c^{2}\right)$ test. Statistical significance was considered at $P<0.05$. In molecular aspect of the study, the identification of the SIT numbers and lineages of isolates was done using SITVIT1Database and Run TB-Lineage. The results of spoligotyping were converted into octal and binary formats, and then entered into query box so that the names of the strains are retrieved from the database if the spoligotype pattern of the strain in question fits the pattern that has already been registered in the SPolDB4 database and at http://www.pasteurguadeloupe.fr:8081/SITVITDemo/ (SITVIT1Database) [20]. If the pattern of the strain in question has not been registered in the database prior to this study, the strain was considered as an orphan. The lineages were also generated by entering binary and octal formats into the query box of SITVIT1Database and Run TB-Lineage.

\section{Abbreviations}

BTB: Bovine tuberculosis; CAS: Central Asian Strain; EA: Euro-American; EAl: East-African-Indian; IO: Indio-Oceanic; LJ: Lowenstein-Jensen; SITVIT: Spoligotype International Types-VNTR International Types; APHA: Plant and Animal Health Agency; UAE: United Arab Emirates; VNTR: Variable Number of DNA Tandem Repeats

\section{Declarations}

Acknowledgements

The authors acknowledge the study participants, owners of the animals and the administrations of the abattoirs and health care provider centers (hospitals and health centers) for their willingness to facilitate the study.

Authors' contributions

TW contributed in the conception and designing of the research, performed field data collection, did the analysis and drafted the manuscript. GM contributed in the conception, designing and in reviewing the manuscript. AZ contributed in the field and laboratory work of the manuscript. MC contributed in the laboratory work of the manuscript. TM contributed in field and laboratory activities of the manuscript and the writing of the manuscript. GA contributed in the conception, designing of the research, supporting in analysis and its interpretation of the data and in reviewing the manuscript. All authors read and approved the final manuscript.

Funding

The study was financially supported by the Office of the Vice President for Research and Graduate Studies of the Addis Ababa University (AAU) under the Thematic research Project entitled as "Mycobacterial Infections in Animals and Their Livestock" with Account Number of 15000018800006223 . The AAU was monitoring the execution of this research project through scientific and financial reports on annual basis. In addition, the final scientific and financial reports were submitted to the AAU.

Competing Interests

The authors declare that there are no competing interests

Availability of data and materials

All data generated and /or analyzed during the current study are not publicly available but they are kept at the Data Management Unit of the Aklilu Lemma Institute of Pathobiology, Addis Ababa University. They can be available by request through the corresponding author.

Ethical approval and consent to participate

The study was approved by the Institutional Review Board (IRB) of the Oromia Health Bureau (Reference No. IRB/BEFO/HBTFH/1-8/3647). Verbal consent was included in the proposal and was approved by the IRB. The IRB approved 
verbal consent since the project was PhD student's research project and did not involve international collaboration and material transfer. Thus, informed consent was obtained verbally from the patients for using sputum samples for this research.

Furthermore, permission was obtained from the owners of animals for post mortem examination and sampling

Consent for publication

Not applicable

\section{References}

1. OIE, 2020. Bovine Tuberculosis. World Organization for Animal Health, OIE, Protecting Animals, Preserving Our Future. https://www.oie.int/animal-health-in-the-world/animal-diseases/bovine-tuberculosis/ Copyright @ OIE 2020

2. Jebara, K.B., Caceres, P., Berlingieri, F., \& Weber-Vintzel, L. Ten years' work on the World Organization for Animal Health (OIE) Worldwide Animal Disease Notification System. Prev. Vet. Med. 2012; 107: 149-159.

3. Ayele, W.Y., Neill, S.D., Zinsstag, J., Weiss, M.G., \& Pavlik, I. Bovine tuberculosis: an old disease but a new threat to Africa. IJTLD. 2004; 8: 924-937.

4. Cosivi O, Grange JM, Daborn CJ, Raviglione MC, Fujikura T, Cousins D, et al. Zoonotic tuberculosis due to Mycobacterium bovis in developing countries. Emerg. Infec. Dis. 1998; 4(1):59-70

5. Cook AJC, Tuchili LM, Buve A, Foster SD, GodfreyFaussett P, Pandey GS, McAdam KPWJ. Human and bovine tuberculosis in the Monze district of Zambia-a cross-sectional study. Br Vet J 1996; 152:37-46.

6. Regassa, A., Medhin, G. and Ameni, G. Bovine tuberculosis is more prevalent in cattle owned by farmers with active tuberculosis in central Ethiopia. Vet. J.2008;178(1): 119-125

7. Kidane, D., Olobo J.O., Habte, A., Negesse, Y., Aseffs, A., Abate, G., Yassin, M.A., Betreda, K., \& Harboe M. Identification of the causative organism of tuberculosis lymphadenitis in Ethiopia by PCR. J. Clin. Microbiol. 2002; 40: 4230-4234.

8. Firdessa, R., Berg, S., Hailu, E., Schelling, E., Gumi, B., Erenso, G. Mycobacterial Lineages Causing Pulmonary and Extrapulmonary Tuberculosis, Ethiopia. Emerg. Infec. Dis. 2013;19 (3):460-463

9. Ashford, D., Whitney, E., Raghunathan, P., \& Cosivi, O. Epidemiology of selected mycobacteria that infect humans and other animals. Rev. Sci. Tech. Int. Off. Epizoot. 2001; 20: 325-337.

10. Kazwala, R., Daborn, C., Kusiluka, L., Jiwa, S., Sharp, J., \& Kambarage, D. Isolation of Mycobacterium species from raw milk of pastoral cattle of the Southern Highlands of Tanzania. Trop. Anim. HIth Prod. 1998; 30: 233-239.

11. Yates, M.D., Pozniak A. \& Grange J.M. Isolation of mycobacteria from patients sero-positive for the human immunodeficiency virus (HIV) in south-east England. Thorax 1993; 48:990-995.

12. WHO, 2020. Tuberculosis (TB). Global tuberculosis report 2019. World Health Organization. https://www.who.int/tb/publications/global_report/en/. @ 2020 WHO

13. Nicholson, M. J., \& Butterworth, M.H. A guide to condition scoring of zebu cattle; International Livestock Research Centre for Africa, 1986, Addis Ababa, Ethiopia.

14. de-Lahunta, A. \& Habel, R.E. Teeth: Applied Veterinary Anatomy; W. B. Sounders Company. USA, 1986; pp. 4-16.

15. Corner, L.A. Post mortem diagnosis of Mycobacterium bovis infection in cattle. Vet. Microbiol. 1994; 40: 53-63.

16. Vordermeier, M., Chambers, M., Cockle, P., Whelan, A., Simmons, J., Hewinson, G. Correlation of ESAT-6-specific gamma interferon production with pathology in cattle following Mycobacterium bovis BCG vaccination against experimental bovine tuberculosis. Infec. Immun. 2002; 70:3026-3032

17. Ameni, G., Aseffa, A., Engers, H., Young, D., Hewinson, G., \& Vordermeier, M. Cattle husbandry in Ethiopia is a predominant factor affecting the pathology of bovine tuberculosis and gamma interferon responses to mycobacterial antigens. Clin. Vaccine Immunol. 2006; 13:1030-1036.

18. Berg, S., Firdessa, R., Habtamu, M., Gadisa, E., Mengistu, A., Yamuah, L., et al. The burden of mycobacterial disease in Ethiopian cattle: implications for public health. PloS one 1009; 4: e5068. 
19. Kamerbeek, J., Schouls, L., Kolk, A., van Agterveld, M., van Soolingen, D., Kuijper, S., et al. Simultaneous detection and strain differentiation of Mycobacterium tuberculosis for diagnosis and epidemiology. J. Clin. Microbiol. 1997; 35: 907-914.

20. Brudey K, Driscoll JR, Rigouts L, Prodinger WM, Gori A, et al. Mycobacterium tuberculosis complex genetic diversity: mining the fourth international spoligotyping database (SpolDB4) for classification population genetics and epidemiology. BMC Microbiol. 2006; 6:23.

21. Ameni, G., \& Wudie, A. Preliminary study on bovine tuberculosis in Nazareth municipality abattoir of central Ethiopia. Bull. Anim. Hlth. Prod. Afr. 2003; 51: 125-132.

22. Teklu, A., Asseged, B., Yimer, E., Gebeyehu, M., \& Woldesenbet, Z. Tuberculous lesions not detected by routine abattoir inspection: the experience of the Hossana municipal abattoir, southern Ethiopia. Rev. Sci. Tech. Int. Office of Epizoo. 2004; 23: 957-964.

23. Mekonnen, G., Conlanb, A.J.K., Berg, S., Ayele, T. B., Alemu, A., Guta, S., Lakew. M., Tadesse, T., Gebre, S. James L.NWood J. L.N., Ameni, G., The ETHICOBOTS consortium. Prevalence of bovine tuberculosis and its associated risk factors in the emerging dairy belts of regional cities in Ethiopia. Preventive Veterinary Medicine 2019; 68: 81-89

24. Carmichael, J. Bovine tuberculosis in the tropics with special reference to Uganda, part II. Vet. J. 1940; 97: 329-339.

25. Ameni, G., Aseffa, A., Engers, H., Young, D., Gordon, S., Hewinson, G., \& Vordermeier, M. High prevalence and increased severity of pathology of bovine tuberculosis in Holsteins compared to Zebu breeds under field cattle husbandry in Central Ethiopia. Clin. Vaccine Immunol. 2007; 14: 1356-1361

26. Vordermeier, M., Ameni, G., \& Glass, E.J. Cytokine responses of Holstein and Sahiwal zebu derived monocytes after mycobacterial infection. Trop. Anim. Hlth Prod. 2012;44: 651-655, DOI: 10.1007/s11250-011-9950-x

27. Aylate, A., Shah, S.N., Aleme, H., \& Gizaw, T.T. Bovine tuberculosis: prevalence and diagnostic efficacy of routine meat inspection procedure in Woldiya municipality abattoir north Wollo zone, Ethiopia. Trop. Anim. Hlth Prod. 2013; 45: 855-864.

28. Desta K, Asrat D, Lemma E, Gebeyehu M, Feleke B. Prevalence of smear negative pulmonary tuberculosis among patients visiting St. Peter's Tuberculosis Specialized Hospital, Addis Ababa, Ethiopia. Ethio. Med. J. 2009;47(1),17-24.

29. Gumi, B., Schelling, E., Berg, S., Firdessa, R., Erenso, G., Mekonnen, W., et al. Zoonotic transmission of tuberculosis between pastoralists and their livestock in South-East Ethiopia. Eco Hlth 2012; 9: 139-149.

30. Firdessa, R., Tschopp, R., Wubete, A., Sombo, M., Hailu, E., \& Erenso, G et al. High Prevalence of Bovine Tuberculosis in Dairy Cattle in Central Ethiopia: Implications for the Dairy Industry and Public Health. PLoS One 2012; 7(12), e52851.

31. Belay, M., Ameni, G., Bjune, G., Couvin, D., Rastogi, N., \& Abebe, F. Strain Diversity of Mycobacterium tuberculosis Isolates from Pulmonary Tuberculosis Patients in Afar Pastoral Region of Ethiopia. BioMed Res. Int. 2014; 1-12, ID 238532, http://dx.doi.org/10.1155/2014/238532

32. Nuru, A., Mamo, G., Teshome, L., Zewdie, A., Medhin, G., Pieper, R., \& Ameni, G., (2015). Bovine tuberculosis and its risk factors among dairy cattle herds in and around Bahir Dar City, Northwest Ethiopia. Ethio. Vet. J. 2015; 19: 27-40.

33. Zewdie, O., Mihret, A., Ameni, G., Worku, A., Gemechu, T., \& Abebe, T. (2016). Molecular typing of mycobacteria isolated from tuberculous lymphadenitis cases in Addis Ababa, Ethiopia. IJTLD 2016; 20: 1529-1534.

34. Ocepek, M., Pate, M., Zolnir-Dovc, M., \& Poljak, M. Transmission of Mycobacterium tuberculosis from human to cattle. J. Clin. Microbiol. 2005; 43: 3555-3557.

35. Prasad, H.K., Singhal, A., Mishra, A., Shah, N.P., \& Katoch, V.M. Bovine tuberculosis in India: potential basis for zoonosis. Tuberculosis (Edinb.) 2005; 85: 421-428.

36. Ameni, G., Vordermeier, M., Firdessa, R., Aseffa, A., Hewinson, G., Stephen, G., et al. Mycobacterium tuberculosis infection in grazing cattle in central Ethiopia. Vet. J. 2011; 188: 359-361.

37. Ameni, G., Tadesse, K., Hailu, E., Deresse, Y., Medhin, G., Aseffa, A. et al. Transmission of Mycobacterium tuberculosis between Farmers and Cattle in Central Ethiopia. Plos One 2013; 8:1-10

38. Lyashchenko, K.P., Greenwald, R., Esfandiari, J., Olsen, J.H., \& Ball, R. Tuberculosis in elephants: antibody responses to defined antigens of Mycobacterium tuberculosis, potential for early diagnosis, and monitoring of treatment. Clin. Vaccine Immunol. 2006; 13: 722-732. 
39. Mamo, G., Kassaye, A., Sanni, M., \& Ameni, A. A cross sectional study of camel tuberculosis in Ethiopia. Bull. Anim. Hlth Prod. Afr. 2009; 57:13-20.

40. Mamo, G., Bayleyegn, G., Sisay, T., Legesse, M., Medhin, G., Bjune, G., Abebe, F., \& Ameni, G. Pathology of camel tuberculosis and molecular characterization of its causative agents in pastoral regions of Ethiopia. PloS One 2011; 6: e15862.

41. Boulahbal, F., Benelmouffok, A. \& Brahimi, K. Role of Mycobacterium tuberculosis in bovine tuberculosis. Arch. Inst. Past. Algé. 1978; 53: 155-164 (In French)

42. Sulieman, M.S., \& Hamid, M.E. Identification of acid-fast bacteria from caseous lesions in cattle in Sudan. J. Vet. Med. 2002; 49: 415-418.

43. Thoen, C.O., Karlson, A.G., \& Himes, E.M. Mycobacterial infections in animals. Rev. Infec. Dis. 1981; 3: 960-972.

44. Idigbe, EO., Anyiwo, CE., \& Onwujekwe DI. Human pulmonary infections with bovine and atypical mycobacteria in Lagos, Nigeria. J. Trop. Med. Hyg. 1986; 89 (3): 143-148.

45. Mawak, J., Gomwalk, N., Bello, C., \& Kandakai-Olukemi, Y. Human pulmonary infections with bovine and environment (atypical) mycobacteria in jos, Nigeria. Ghana Med. J. 2006; 40: 132-136.

46. Addo, K., Owusu-Darko, K., Yeboah-Manu, D., Caulley, P., Minamikawa, M., \& Bonsu, F. Mycobacterial Species Causing Pulmonary Tuberculosis at the Korle Bu Teaching Hospital, Accra, Ghana. Ghana Med. J. 2007; 41 (2): 52-57.

\section{Tables}

Table 1. Association of selected risk factors with the percentage of lesion BTB at Adama and Bishoftu abattoirs

Variable

Number of cattle examined

Number (\%) Pair-wise comparison positive

Chi-square $\left(\chi^{2}\right)$ test

Pvalue

\section{Origin of animal}

\begin{tabular}{|c|c|c|c|c|c|}
\hline \multicolumn{5}{|l|}{$\begin{array}{l}\text { (Arsi, Bale and Borena } \\
\text { zones) }\end{array}$} & $<0.001$ \\
\hline \multicolumn{6}{|l|}{$\begin{array}{l}\text { (Afar, Harar, Wollo } \\
\text { zones) }\end{array}$} \\
\hline $\begin{array}{l}\text { West to the study site } \\
\text { (Wellega zones) }\end{array}$ & 285 & $13(4.6)$ & Northeast versus West & 9.08 & $<0.01$ \\
\hline \multicolumn{6}{|l|}{ Abattoir } \\
\hline Adama abattoir & 1266 & $32(2.5)$ & & 27.21 & $<0.001$ \\
\hline Bishoftu export abattoir & 630 & $48(7.6)$ & & & \\
\hline \multicolumn{6}{|l|}{ Body condition } \\
\hline Lean & 460 & $33(7.2)$ & Lean versus Medium & 1.54 & $>0.05$ \\
\hline Medium & 440 & $23(5.2)$ & Lean versus Good & 19.25 & $<0.001$ \\
\hline Good & 996 & $24(2.4)$ & Medium versus Good & 7.59 & $<0.01$ \\
\hline Total & 1896 & 80 & & & \\
\hline
\end{tabular}


Table 2. Distribution and frequency of TB lesions in the lymph nodes and organs of cattle slaughtered at Adama and Bishoftu abattoirs, central Ethiopia

\begin{tabular}{|c|c|c|c|c|c|c|c|}
\hline \multirow[t]{2}{*}{ Organs } & \multicolumn{7}{|c|}{ Postmortem findings } \\
\hline & $\begin{array}{l}\text { Number of } \\
\text { organs with } \\
\text { lesion }\end{array}$ & $\begin{array}{l}\text { Percent of } \\
\text { organs } \\
\text { with lesion }\end{array}$ & $\begin{array}{l}\text { Summary on the } \\
\text { basis of } \\
\text { anatomical sites }\end{array}$ & $\begin{array}{l}\text { Percent } \\
\text { of } \\
\text { lesion }\end{array}$ & $\begin{array}{l}\text { Pairwise } \\
\text { comparison }\end{array}$ & $\begin{array}{l}c^{2}(95 \% \\
\text { confidence } \\
\text { interval) }\end{array}$ & $\begin{array}{l}P \\
\text { value }\end{array}$ \\
\hline Lungs & 14 & $17.5 \%$ & Head/neck region & $26.3 \%$ & & & \\
\hline $\begin{array}{l}\text { Bronchial lymph } \\
\text { nodes (LN) }\end{array}$ & 17 & $21.3 \%$ & Thoracic cavity & $52.5 \%$ & $\begin{array}{l}\text { Head/neck } \\
\text { region and } \\
\text { thoracic cavity }\end{array}$ & $\begin{array}{l}11.43 \\
(11.08 \\
39.71)\end{array}$ & $<0.001$ \\
\hline Mediastinal LN & 11 & $13.7 \%$ & Abdominal cavity & $13.7 \%$ & $\begin{array}{l}\text { Head/neck } \\
\text { region and } \\
\text { abdominal } \\
\text { cavity }\end{array}$ & $\begin{array}{l}3.88 \\
(0.02, \\
24.61)\end{array}$ & $P=0.05$ \\
\hline $\begin{array}{l}\text { Retropharyngeal } \\
\text { LN }\end{array}$ & 17 & $21.3 \%$ & Pre-scapular LN & $7.5 \%$ & $\begin{array}{l}\text { Head/neck } \\
\text { region and pre- } \\
\text { scapular LN }\end{array}$ & $\begin{array}{l}10.00 \\
(7.26 \\
30.11)\end{array}$ & $<0.01$ \\
\hline Mandibular LN & 4 & $5.0 \%$ & & & $\begin{array}{l}\text { Thoracic cavity } \\
\text { and abdominal } \\
\text { cavity }\end{array}$ & $\begin{array}{l}26.86 \\
(24.49 \\
50.81)\end{array}$ & $<0.001$ \\
\hline Mesenteric LN & 6 & $7.5 \%$ & & & $\begin{array}{l}\text { Thoracic cavity } \\
\text { and pre-scapular } \\
\text { LN }\end{array}$ & $\begin{array}{l}38.33 \\
(31.61, \\
56.31)\end{array}$ & $<0.001$ \\
\hline Pre-scapular LN & 6 & $7.5 \%$ & & & $\begin{array}{l}\text { Abdominal } \\
\text { cavity and pre- } \\
\text { scapular LN }\end{array}$ & $\begin{array}{l}1.66 \\
(-3.52 \\
16.26)\end{array}$ & $>0.05$ \\
\hline Liver & 5 & $6.2 \%$ & & & & & \\
\hline Total & 80 & $100 \%$ & & $100 \%$ & & & \\
\hline
\end{tabular}

Table 3. Selected demographic characteristics of the study participants and their association with culture positivity 


$\begin{array}{lllll}\begin{array}{l}\text { Number }(\%) \\ \text { positive }\end{array} & \text { Total } & \begin{array}{l}\text { Pairwise } \\ \text { comparison }\end{array} & \begin{array}{l}\text { Chi-square test }(95 \% \text { confidence interval, } \\ \text { Cl) }\end{array} & \begin{array}{l}\mathrm{P} \\ \text { value }\end{array}\end{array}$

\begin{tabular}{|c|c|c|c|c|c|}
\hline \multicolumn{6}{|l|}{ Adama Town } \\
\hline \multicolumn{6}{|l|}{ Age } \\
\hline $\begin{array}{l}\text { Group 1: 10- } \\
29\end{array}$ & $12(10.3 \%)$ & 116 & $\begin{array}{l}\text { Group } 1 \text { and Group } \\
2\end{array}$ & $6.48(2.8,20.8)$ & $P<0.05$ \\
\hline $\begin{array}{l}\text { Group 2: } 30- \\
59\end{array}$ & $31(22.3 \%)$ & 139 & $\begin{array}{l}\text { Group } 1 \text { and Group } \\
3\end{array}$ & $9.40(7.5,49.00)$ & $\mathrm{p}<0.01$ \\
\hline Group 3: $\geq 60$ & $7(36.8 \%)$ & 19 & $\begin{array}{l}\text { Group } 2 \text { and Group } \\
3\end{array}$ & $1.9(-4.8,37.5)$ & $p>0.05$ \\
\hline Total & 50 & 274 & & & \\
\hline \multicolumn{6}{|l|}{ Sex } \\
\hline Female & $25(18.4 \%)$ & 136 & & $0.0(-8.9,9.5)$ & $p>0.05$ \\
\hline Male & $25(18.1 \%)$ & 138 & & & \\
\hline Total & 50 & 274 & & & \\
\hline \multicolumn{6}{|l|}{ Residence } \\
\hline Rural & 34 (18.5\%) & 184 & & $0.32(-6.9,14.8)$ & $P>0.05$ \\
\hline Urban & $16(21.6 \%)$ & 90 & & & \\
\hline Total & 50 & 274 & & & \\
\hline \multicolumn{6}{|l|}{$\begin{array}{l}\text { Bishoftu } \\
\text { Town }\end{array}$} \\
\hline \multicolumn{6}{|l|}{ Age } \\
\hline $\begin{array}{l}\text { Group 1: 10- } \\
29\end{array}$ & $15(31.9 \%)$ & 48 & $\begin{array}{l}\text { Group } 1 \text { and Group } \\
2\end{array}$ & $0.68(-9.7,24.3)$ & $p>0.05$ \\
\hline $\begin{array}{l}\text { Group 2: } 30- \\
59\end{array}$ & $14(24.6 \%)$ & 58 & $\begin{array}{l}\text { Group } 1 \text { and Group } \\
3\end{array}$ & $1.5(-9.1,44.0)$ & $p>0.05$ \\
\hline Group 3: $\geq 60$ & $7(50 \%)$ & 14 & $\begin{array}{l}\text { Group } 2 \text { and Group } \\
3\end{array}$ & $3.38(-1.2,50.5)$ & $p>0.05$ \\
\hline Total & 36 & 120 & & & \\
\hline \multicolumn{6}{|l|}{ Sex } \\
\hline Female & 20 & 63 & & $0.17(-13.0,19.5)$ & $p>0.05$ \\
\hline Male & 16 & 57 & & & \\
\hline Total & 36 & 120 & & & \\
\hline \multicolumn{6}{|l|}{ Residence } \\
\hline Rural & 10 & 46 & & $2.34(-3.8,28.4)$ & $p>0.05$ \\
\hline Urban & 26 & 74 & & & \\
\hline Total & 36 & 120 & & & \\
\hline
\end{tabular}

Table 4. Spoligotype patterns of M. bacterium tuberculosis complex species isolated from cattle in East Shewa, central Ethiopia 
Page 15/19 


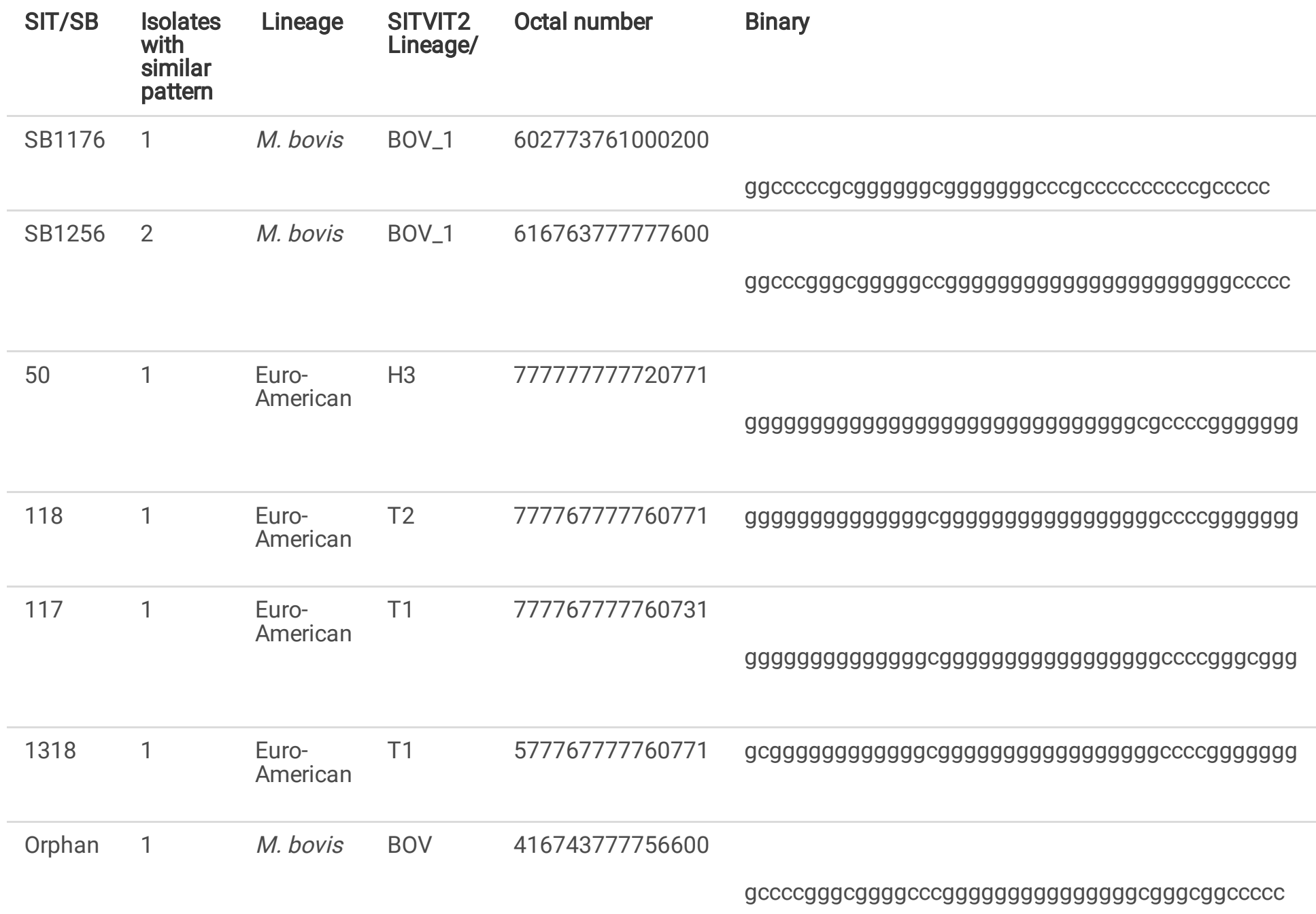

\begin{tabular}{|c|c|c|c|c|c|}
\hline Orphan & 1 & M. bovis & BOV_1 & 612763761000200 & 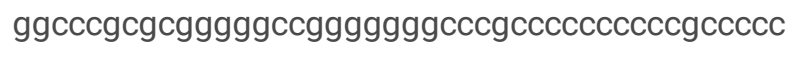 \\
\hline Orphan & 1 & M. bovis & BOV_1 & 612773761000200 & \\
\hline
\end{tabular}

\begin{tabular}{|c|c|c|c|c|c|}
\hline Orphan & 1 & M. bovis & BOV_1 & 400201434200000 & geccecceccgecceccggeccgggeccgeccecceccecccc \\
\hline Orphan & 1 & M. bovis & BOV_1 & 402773761000200 & gccccccgcggggggcggggggggcccgeccсcсcсcсgсcсcc \\
\hline Orphan & 2 & M. bovis & BOV_1 & 416763577756600 & gccccgggcgggggccgggcggggggggggggegggeggecccc \\
\hline \multirow[t]{2}{*}{ Orphan } & 2 & M. bovis & BOV_1 & 612773761000200 & \\
\hline & & & & & 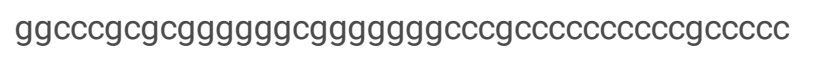 \\
\hline Orphan & 1 & $\begin{array}{l}\text { Euro- } \\
\text { American }\end{array}$ & $\mathrm{H} 3$ & 577767777700771 & \\
\hline
\end{tabular}




\begin{tabular}{llll}
\hline Orphan 1 & $\begin{array}{l}\text { Indo- } \\
\text { Oceanic }\end{array}$ & MANU1 & 777767777777771 \\
\hline
\end{tabular}

ggggggggggggggcogggggggggggggggggggggggggggg

$\begin{array}{lllll}\text { Orphan } & 1 & \begin{array}{l}\text { Euro- } \\ \text { American }\end{array} & \mathrm{T} & 775767577760771\end{array}$

gggggggcogggggeggggcoggggggggggggecccggggggg

\begin{tabular}{lllll}
\hline Orphan & 1 & $\begin{array}{l}\text { Euro- } \\
\text { American }\end{array}$ & T & 777767777760661 \\
& & &
\end{tabular}

gggggggggggggggcgggggggggggggggggggccccggcggcg

$\begin{array}{lllll}\text { Orphan } & 1 & \text { Euro- } \\ \text { American } & \mathrm{X} & 417763575600200 & \text { gccccggggggggggccgggegggggcgggccccccccgccccc }\end{array}$

Table 5. Spoligotype patterns of M. tuberculosis complex species isolated from humans in East Shewa, central Ethiopia. 


\begin{tabular}{|c|c|c|c|c|c|}
\hline SIT & $\begin{array}{l}\text { Isolates with similar } \\
\text { pattern }\end{array}$ & Lineage & $\begin{array}{l}\text { SITVIT2 } \\
\text { sublineage }\end{array}$ & Octal number & Binary \\
\hline \multirow[b]{2}{*}{149} & 18 & EA & T3 ETH & & \multirow{3}{*}{$\begin{array}{l}\text { ggggggggggcccccccccccoggggggggggggggccccoggggggg } \\
\text { gggggggggggggggggggggggggggccegcccogggggg }\end{array}$} \\
\hline & \multirow{2}{*}{3} & \multirow[b]{2}{*}{ EA } & \multirow{2}{*}{$\mathrm{H} 4$} & 777000377760771 & \\
\hline 777 & & & & 777777777420771 & \\
\hline \multirow{2}{*}{336} & 2 & EA & & & \multirow[t]{2}{*}{ 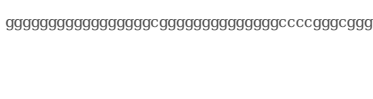 } \\
\hline & 11 & EA & $\begin{array}{l}\mathrm{Al} \\
\mathrm{T} 1\end{array}$ & & \\
\hline \multirow[t]{2}{*}{53} & \multirow[b]{2}{*}{2} & \multirow[b]{2}{*}{ EA } & & 777777777760771 & \multirow[t]{2}{*}{ 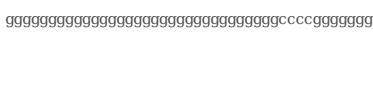 } \\
\hline & & & & & \\
\hline 50 & & & H3 & 777777777720771 & ggygggggggggggggggggggggggggggggcgccccogggggga \\
\hline 134 & 3 & EA & H3 & 777777777720631 & gggggggggggggggggggggggggggggggccocccoggcoggg \\
\hline 1745 & 1 & EA & T3 & 773737777760771 & 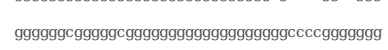 \\
\hline 245 & 1 & EA & $\mathrm{T} 1$ & 777777777760671 & 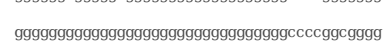 \\
\hline 37 & 4 & EA & T3 & 777737777760771 & ggggggggggggocgggggggggggggggggggggcccoggggggg \\
\hline 221 & 1 & EA & $\mathrm{X} 1$ & 777766777760771 & gggggggggggggggcggcogggggggggggggocccoggggggg \\
\hline 1221 & 1 & EA & T1 & 757767777760771 & ggggcogggggggggceggggggggggggggggggccccoggggggg \\
\hline 1547 & 4 & EA & T3 & 777727777760771 & gggggggggggggcgcggggggggggggggggggccccgggggggg \\
\hline 51 & 1 & EA & $\mathrm{T}$ & 777777777760700 & ggggggggggggggggggggggggggggggggggcccogggccco \\
\hline 75 & 1 & EA & H3 & 777767777720771 & gggggggggggggggcogggggggggggggggcgccccgggggggg \\
\hline 7 & 1 & EA & T1 & 377777777760771 & 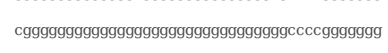 \\
\hline 118 & 6 & EA & $\mathrm{T} 2$ & 777767777760771 & 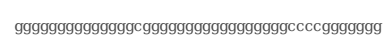 \\
\hline 1318 & 3 & EA & T1 & 577767777760771 & gc gggggggggggggcgggggggggggggggggggcccoggggggg \\
\hline 117 & 3 & EA & $\mathrm{T} 1$ & 777767777760731 & gggggggggggggggcogggggggggggggggggccccgggcoggg \\
\hline 1687 & 1 & EA & T1 & 777767775760771 & 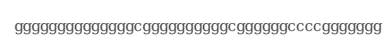 \\
\hline 1802 & 1 & EA & H3 & 777767777720631 & gggggggggggggggcogggggggggggggggcgccccoggccogg \\
\hline 611 & 1 & EA & T1 & 777767777560771 & gggggggggggggggecggggggggggggggc gggeccccggggggg \\
\hline 834 & \multirow{2}{*}{1} & EA & $\mathrm{U}$ & 777767777740771 & \multirow{2}{*}{ 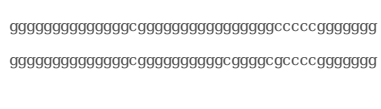 } \\
\hline 116 & & & H3 & 777767775720771 & \\
\hline Orphan & 1 & $\begin{array}{l}\text { EA } \\
\text { EA }\end{array}$ & H3 & 477767777720571 & gcc ggggggggggggc ggggggggggggggggcgcccccgcgggggg \\
\hline Orphan & 1 & EA & $\mathrm{X} 2$ & 777737777760000 & gggggggggggggc ggggggggggggggggggggcccccccccccc \\
\hline Orphan & 1 & EA & $\mathrm{T}$ & 755777777760671 & ggggcggcggggggggggggggggggggggggggccccoggcgggg \\
\hline Orphan & 1 & EA & $\mathrm{X} 2$ & 777727777760000 & \multirow{3}{*}{ 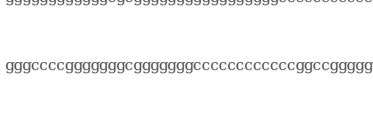 } \\
\hline \multirow{2}{*}{309} & 1 & EAI & & & \\
\hline & 1 & $F \Lambda$ & CASI & 703/6/740003171 & \\
\hline \multirow[t]{2}{*}{25} & 1 & EAl & CAS1 & 703777740003171 & \multirow[t]{2}{*}{ gygcccecggggggggggggggggccccccccccecoggccggggg } \\
\hline & 2 & EAI & MTB CAS & & \\
\hline 141 & & \multirow[b]{2}{*}{ EAI } & & 703767740003771 & 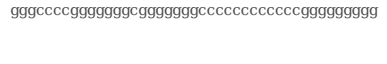 \\
\hline Orphan & 1 & & CAS & 703777400002061 & gggcccc gggggggggggggecceccccccccccccogccccoggcg \\
\hline & & $M-$ & & & \\
\hline Orphan & 2 & $\begin{array}{l}\text { africanum } \\
M-\end{array}$ & Manu2 & 575347777763661 & gcgggggcgcoggccogggggggggggggggggccogggcggcg \\
\hline Orphan & 1 & africanum & $\mathrm{X} 2$ & 554377777760660 & gc⿻ \\
\hline Orphan & 1 & IO & CAS & 713600000001171 & 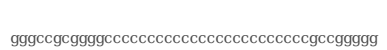 \\
\hline 1443 & 2 & M. bovis & $\mathrm{BOV}$ & 616777777777600 & gagce \\
\hline
\end{tabular}

\section{Figures}




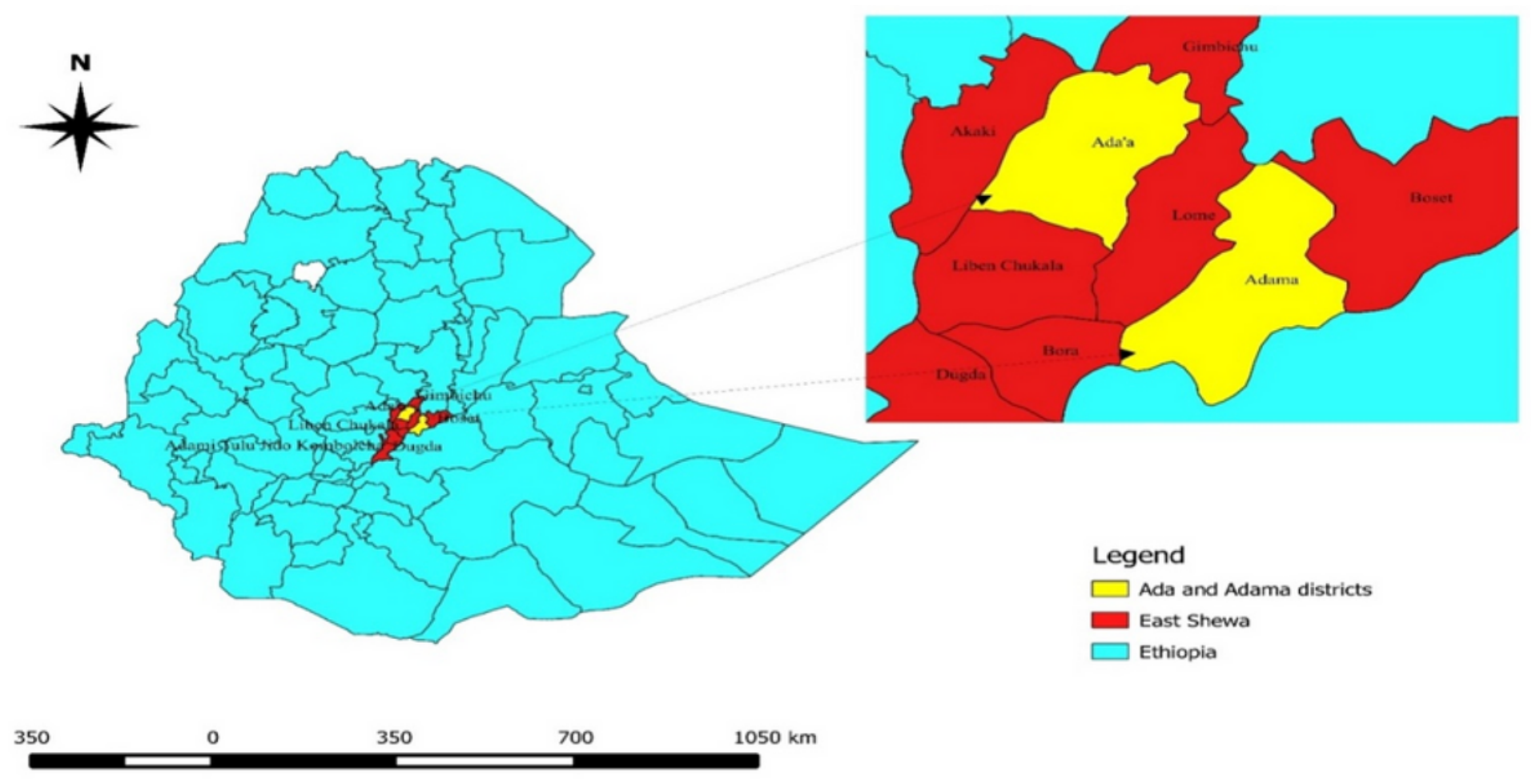

Figure 1

Location of the study area on the map of Ethiopia. 